\title{
Salt, endogenous ouabain and blood pressure interactions in the general population
}

\author{
Ji-Guang Wang ${ }^{a}$, Jan A. Staessen ${ }^{a}$, Elisabetta Messaggio ${ }^{b}$, Tim Nawrot $^{a}$, \\ Robert Fagard $^{a}$, John M. Hamlyn ${ }^{c}$, Giuseppe Bianchib and Paolo Manunta ${ }^{b}$
}

\begin{abstract}
Objective Experimental data show that ouabain is a modulator of the sodium - potassium pump, which plays an important role in sodium homeostasis and blood pressure regulation. We investigated the distribution of plasma ouabain in the general population in relation to blood pressure and other determinants of sodium homeostasis.

Methods In 379 subjects enrolled in a Belgian population study, we measured plasma ouabain, clinical characteristics including blood pressure, serum and urinary electrolytes, urinary aldosterone excretion, various lifestyle factors, and the Gly460Trp polymorphism of the $\alpha$ adducin gene. Our statistical methods included analysis of covariance and multiple linear regression.
\end{abstract}

Results Plasma ouabain (median, $140 \mathrm{pmol} / \mathrm{l}$ ) correlated independently and positively with male gender $(n=182$, $P=0.002)$, smoking $(n=116, P=0.05)$, urinary potassium excretion (mean $69 \mathrm{mmol} /$ day, $P<0.0001$ ), and mutation of the $\alpha$-adducin gene $(n=161, P<0.0001)$. Both before and after adjustment for covariables, continuous as well as categorical analyses revealed a significant interaction $(P \leqslant 0.02)$ between plasma ouabain and urinary sodium excretion (mean $194 \mathrm{mmol} /$ day) in relation to blood pressure (mean systolic blood pressure/diastolic blood pressure, $123 / 76 \mathrm{mmHg}$ ). In individuals with plasma ouabain values below the median, blood pressure increased by $2.2 \mathrm{mmHg}$ systolic and $1.4 \mathrm{mmHg}$ diastolic for each $50 \mathrm{mmol} /$ day increment in urinary sodium excretion $(P \leqslant 0.01)$. No association between blood

\section{Introduction}

Endogenous ouabain is released from the adrenal gland and possibly from the hypothalamus [1-5]. The hypothesis gaining ground is that endogenous ouabain behaves as a versatile modulator of the ubiquitously expressed $\mathrm{Na}^{+} / \mathrm{K}^{+}$-ATPase (sodium-potassium pump) [6], which plays an important role in sodium homeostasis and regulation of blood pressure [7]. In rats, chronic low-dose infusion of exogenous ouabain produces hypertension [8]. In humans, hypertension [9], pre-eclampsia [10] and left ventricular dysfunction [11] are associated with increased plasma concentration of endogenous ouabain.

In addition to endogenous ouabain, many other genetic pressure and urinary sodium excretion was found when plasma ouabain exceeded the median.

Conclusions Plasma ouabain behaves as a blood pressure modulating factor, possibly released in response to potassium, either inhibiting the pressor effect of an excessive salt intake or counteracting the depressor action of sodium depletion. J Hypertens 21:1475-1481 $\odot 2003$ Lippincott Williams \& Wilkins.

Journal of Hypertension 2003, 21:1475-1481

Keywords: endogenous ouabain, adducin, urinary sodium and potassium, blood pressure

aHypertensie en Cardiovasculaire Revalidatie Eenheid, Departement voor Moleculair en Cardiovasculair Onderzoek, Katholieke Universiteit Leuven, Leuven Belgium, ${ }^{b}$ Cattedra e Scuola di Nefrologia, Università Vita e Salute San Raffaele, Milano, Italy and ${ }^{\mathrm{C}}$ Department of Physiology, School of Medicine, University of Maryland, Baltimore, Maryland, USA.

Sponsorship: The FLEMENGHO study was supported by research grants G.0291.98 and G.0424.03 from the Fonds voor Wetenschappelijk Onderzoek Vlaanderen (Brussels, Belgium), the Bilateral Scientific and Technical Collaboration between Flanders and China (project BIL02/10), a special research grant from the University of Leuven (Onderzoekstoelage OT99/28), a grant from the Ministero della Sanità (Milan, Italy) to Giuseppe Bianchi (RF20000-49), and funds from the European Union (contract number IC15-CT98-0329EPOGH and QLG1-CT-2000-01137-EURNETGEN).

Correspondence and requests for reprints to $\mathrm{Dr}$ Jan A. Staessen, Study Coordinating Centre, Laboratory of Hypertension, Department of Molecular and Cardiovascular Research, Campus Gasthuisberg, University of Leuven, Herestraat 49, B-3000 Leuven, Belgium.

Tel: +32 1634 7104; fax: +32 16347106 ;

e-mail: jan.staessen@med.kuleuven.ac.be

Received 7 February 2003 Revised 15 April 2003 Accepted 28 April 2003

[12,13] and lifestyle [14] factors potentially interfere with $\mathrm{Na}^{+} / \mathrm{K}^{+}$-ATPase activity. For example, substitution of glycine by tryptophan at position 460 of the $\alpha$-subunit of the heterodimeric cytoskeleton protein adducin (Gly460Trp polymorphism) leads to increased $\mathrm{Na}^{+} / \mathrm{K}^{+}$-ATPase activity $[12,13]$ and induces sodium retention $[15,16]$. Potassium supplementation may upregulate $\mathrm{Na}^{+} / \mathrm{K}^{+}$-ATPase activity [14].

At present, little is known about the plasma concentration of endogenous ouabain in the population at large and on the association of this hormone with blood pressure or other factors influencing sodium homeostasis. We therefore investigated these issues in Caucasian subjects randomly selected from a Belgian population. 


\section{Methods}

\section{Study population}

The protocol of the Flemish Study on Environment, Genes and Health Outcomes (FLEMENGHO) was approved by the Ethics Committee of the University of Leuven. All subjects gave informed consent. From August 1985 to December 2000, a random sample of the households living in a geographically defined area of Northern Belgium was investigated [17]. The present cross-sectional study involved 452 subjects recruited in the year 2000. The participation rate among the subjects contacted was $66.1 \%$. Fifty-seven subjects declined to collect a 24-h urine sample, and 16 had incomplete measurements including urinary volume $(n=1)$, endogenous ouabain concentration $(n=14)$ or $\alpha$-adducin genotype $(n=1)$. Thus, the number of subjects included in the present analysis totalled 379 .

\section{Field work}

Study nurses repeatedly visited the participants in their homes. The same observer measured a subject's blood pressure five times consecutively at each of two home visits 4-6 weeks apart. Conventional sphygmomanometry was performed according to the guidelines of the British Hypertension Society after the subjects had rested for $5 \mathrm{~min}$ in the sitting position. For analysis, we averaged the 10 blood pressure readings. Hypertension was diagnosed if the average blood pressure was at least $140 \mathrm{mmHg}$ systolic or $90 \mathrm{mmHg}$ diastolic, or when the patients were on antihypertensive medication.

We used a validated [18] questionnaire to collect information on medical history, smoking habits, alcohol intake and use of medications. In the interval between the two home visits, the participants collected a 24-h urine sample in a wide neck plastic container for the measurement of sodium, potassium, aldosterone and creatinine. Venous blood was sampled, usually within 2 weeks after the urine collection, for measurement of plasma ouabain and the serum concentration of sodium and potassium.

\section{Laboratory methods}

Endogenous ouabain was extracted from plasma and measured by a specific radio-immunoassay as previously described [3]. The immuno-crossreactivity of the antiserum was $100 \%$ for ouabain; for digoxin it was only 0.42 and $0.04 \%$ before and after extraction of plasma on C18 columns, respectively. The threshold sensitivity of the antiserum was $20 \mathrm{pmol} / \mathrm{l}$. In ouabain dilution experiments, the $\mathrm{EC}_{50}$ displacement was at 200$300 \mathrm{pmol} / \mathrm{l}$. The intra-assay and inter-assay coefficients of variations were 7 and $10 \%$, respectively [3]. In the context of this article, the term 'plasma ouabain' refers to the concentration of the endogenous compound. Urinary aldosterone was also measured by radioimmunoassay. The serum and urinary concentrations of sodium and potassium were determined by flame photometry.

Genomic DNA was extracted from peripheral blood. Allelic discrimination of the Gly460Trp $\alpha$-adducin polymorphism was carried out as previously described [17] using the $5^{\prime}$ nuclease assay on an ABI Prism 7700 apparatus (Perkin Elmer, Foster City, California, USA).

\section{Statistical analysis}

For database management and statistical analysis, we used SAS software, version 8.1 (SAS Institute, Cary, North Carolina, USA). Measurements with a skewed distribution were normalized by logarithmic transformation. Means and proportions were compared with the standard normal $\%$ test and Fisher's exact test, respectively. We searched for possible confounders using stepwise multiple regression with the $P$ value for covariables to enter and stay in the model set at 0.15 . We used analysis of covariance and multiple linear regression to test associations of interest, while controlling for covariables.

\section{Results}

\section{Characteristics of the participants}

The 182 male and 197 female participants had similar mean age (Table 1). Men had slightly higher body mass index than women $(P=0.02)$. Among men, $33.5 \%$ $(n=62)$ were current smokers and $48.4 \% \quad(n=88)$ reported intake of alcohol. In women, these proportions were $27.4 \%(n=54)$ and $21.8 \%(n=43)$, respectively. Fifty-seven women (28.9\%) used oral contraceptives and eight $(4.1 \%)$ took hormonal replacement therapy. The study sample included 82 hypertensive patients, of whom 44 took antihypertensive drugs ( $\beta$-blockers, $n=26$; diuretics, $n=10$; calcium-channel blockers, $n=7$; centrally acting agents, $n=3$; angiotensinconverting enzyme inhibitors, $n=2$; and $\alpha$-blockers $n=2)$.

In stepwise multiple regression, we considered gender, age, body mass index, smoking, alcohol intake, serum total cholesterol, and use of $\beta$-blockers, diuretics or oral contraceptives as potential correlates of plasma ouabain. Of these variables, only gender $(P=0.002)$ and smoking $(P=0.05)$ entered the model. Plasma ouabain was higher in men than women (Table 1 ), and in smokers than non-smokers (157.8 versus $147.5 \mathrm{pmol} / \mathrm{l})$, but it was neither dependent on age nor body mass index $(P>0.80)$. In men $(r=0.26, P=0.0004)$ and women $(r=0.14, P=0.05)$, haematocrit increased with higher plasma ouabain concentration. In all further analyses with plasma ouabain as the dependent variable, we allowed for gender and smoking. 
Table 1. Characteristics of the participants

\begin{tabular}{lccc}
\hline Characteristic & $\begin{array}{c}\text { Men } \\
(\mathrm{n}=182)\end{array}$ & $\begin{array}{c}\text { Women } \\
(\mathrm{n}=197)\end{array}$ & $P^{*}$ \\
\hline Age (years) & $40.0 \pm 17.3$ & $40.4 \pm 16.9$ & 0.80 \\
Body mass index $\left(\mathrm{kg} / \mathrm{m}^{2}\right)$ & $25.2 \pm 3.8$ & $24.2 \pm 4.5$ & 0.02 \\
Systolic blood pressure $(\mathrm{mmHg})$ & $125.9 \pm 13.5$ & $120.3 \pm 14.9$ & $<0.0001$ \\
Diastolic blood pressure $(\mathrm{mmHg})$ & $78.6 \pm 10.8$ & $74.5 \pm 9.4$ & $<0.0001$ \\
Pulse rate (beat/min) & $67.1 \pm 7.5$ & $69.8 \pm 7.9$ & $<0.0001$ \\
Hypertensive patients $(\%)$ & $51(28.0)$ & $31(15.7)$ & 0.004 \\
Treated hypertensive patients $(\%)$ & $25(13.7)$ & $19(9.6)$ & 0.26 \\
Plasma ouabain concentration (pmol/l) & $158 \pm 48$ & $144 \pm 45$ & 0.002 \\
Serum $\mathrm{Na}^{+}$concentration $(\mathrm{mmol} / \mathrm{l})$ & $141.9 \pm 2.6$ & $141.3 \pm 2.4$ & 0.04 \\
Serum $\mathrm{K}^{+}$concentration $(\mathrm{mmol} / \mathrm{l})$ & $4.17 \pm 0.31$ & $4.11 \pm 0.32$ & 0.07 \\
Urinary volume $(/ /$ day) & $1.49 \pm 0.68$ & $1.54 \pm 0.75$ & 0.51 \\
Creatinine excretion $(\mathrm{mmol} / \mathrm{day})$ & $13.2 \pm 3.5$ & $8.9 \pm 2.1$ & $<0.0001$ \\
Sodium excretion $(\mathrm{mmol} / \mathrm{day})$ & $212 \pm 64$ & $176 \pm 52$ & $<0.0001$ \\
Potassium excretion $(\mathrm{mmol} / \mathrm{day})$ & $76 \pm 28$ & $62 \pm 22$ & $<0.0001$ \\
Urinary Na $/ \mathrm{K}^{+}$ratio & $3.00 \pm 1.02$ & $3.05 \pm 1.03$ & 0.63 \\
Aldosterone excretion (nmol/day) & $18.5(16.3-20.9)$ & $20.8(18.3-23.7)$ & 0.20 \\
\hline
\end{tabular}

Values are arithmetic means \pm standard deviation, geometric means (95\% confidence interval) or number of subjects (\% of column total). * For gender difference.

\section{Association between plasma ouabain and the $\alpha$-adducin Gly460Trp polymorphism}

The frequencies of the $\alpha$-adducin genotypes did not deviate from Hardy-Weinberg equilibrium (GlyGly, 0.58; GlyTrp, 0.36; TrpTrp, 0.06; $P=0.85$ ). Characteristics of the subjects were similar across the $\alpha$-adducin genotypes. Both before and after (Fig. 1) adjustment for gender and smoking, plasma ouabain was significantly $(P<0.0001$ for trend) associated with the number of copies of the $\alpha$-adducin Trp allele. Compared with GlyGly homozygotes, plasma ouabain was 14.4 pmol/l higher $[95 \%$ confidence interval (CI), 4.9$23.9 \mathrm{pmol} / \mathrm{l} ; \quad P=0.003)$ in Gly Trp heterozygotes and $29.5 \mathrm{pmol} / \mathrm{l}$ higher (95\% CI, $10.7-48.4 \mathrm{pmol} / \mathrm{l} ; \quad P=$ $0.002)$ in TrpTrp homozygotes.

\section{Association between plasma ouabain and urinary sodium and potassium excretion}

After adjustment for gender, smoking and the $\alpha$ adducin Gly460Trp polymorphism, plasma ouabain was significantly $(P<0.0001)$ and positively associated with urinary potassium excretion (Fig. 2), but it was neither dependent on urinary sodium excretion nor on the serum concentration of sodium or potassium $(P>0.11)$. Each $25 \mathrm{mmol} /$ day increase in urinary potassium excretion was associated with a $9.1 \mathrm{pmol} / \mathrm{l}$ increment in plasma ouabain (95\% CI, 4.7-13.5 pmol/l). This association was independent of the serum concentration of potassium. As expected, a linear and positive association between urinary aldosterone excretion and urinary potassium excretion was also observed $(P<0.0001)$ (Fig. 2). However, with similar adjustments as before, there was only a weak positive relationship between plasma ouabain and urinary aldosterone excretion $(r=$ $0.07, P=0.20$ ).

Association between plasma ouabain and blood pressure After adjustment for gender, age, age ${ }^{2}$, body mass
Fig. 1

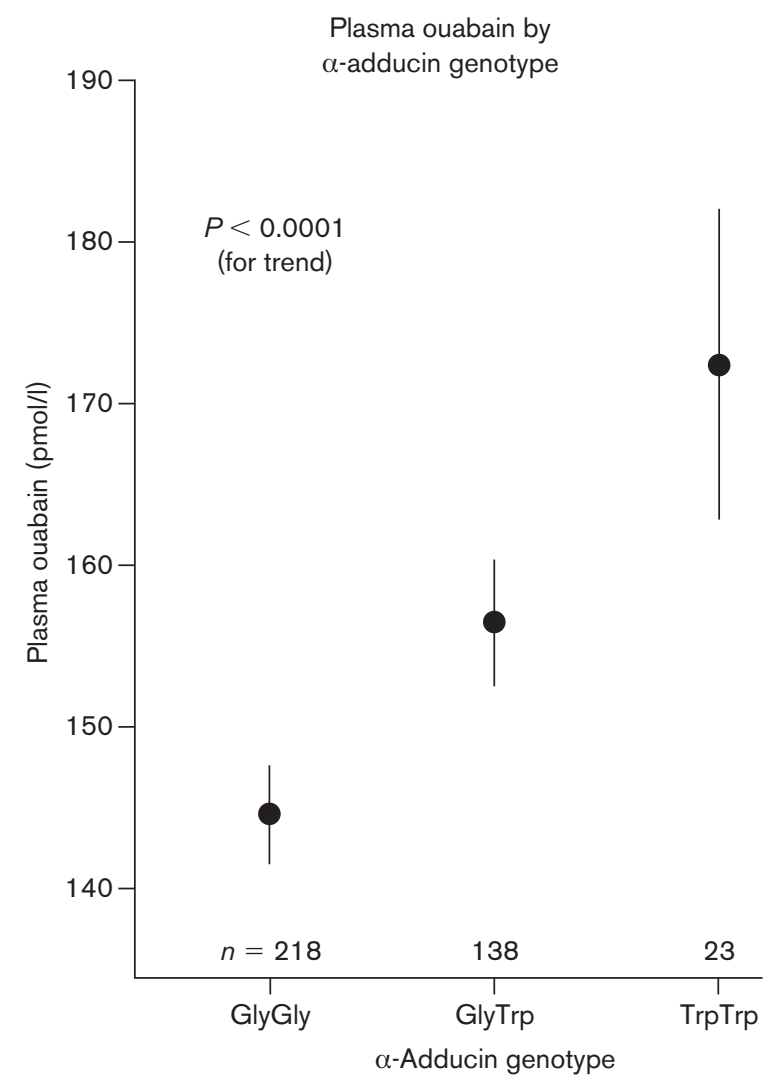

Association between plasma ouabain concentration and the $\alpha$-adducin Gly460Trp polymorphism. Values are means \pm standard error, adjusted for gender and smoking. $n$ indicates number of subjects per genotype.

index, smoking, alcohol intake, use of antihypertensive drugs or oral contraceptives, and the $\alpha$-adducin Gly460Trp polymorphism, the systolic and diastolic blood pressures were not significantly associated with 
Fig. 2

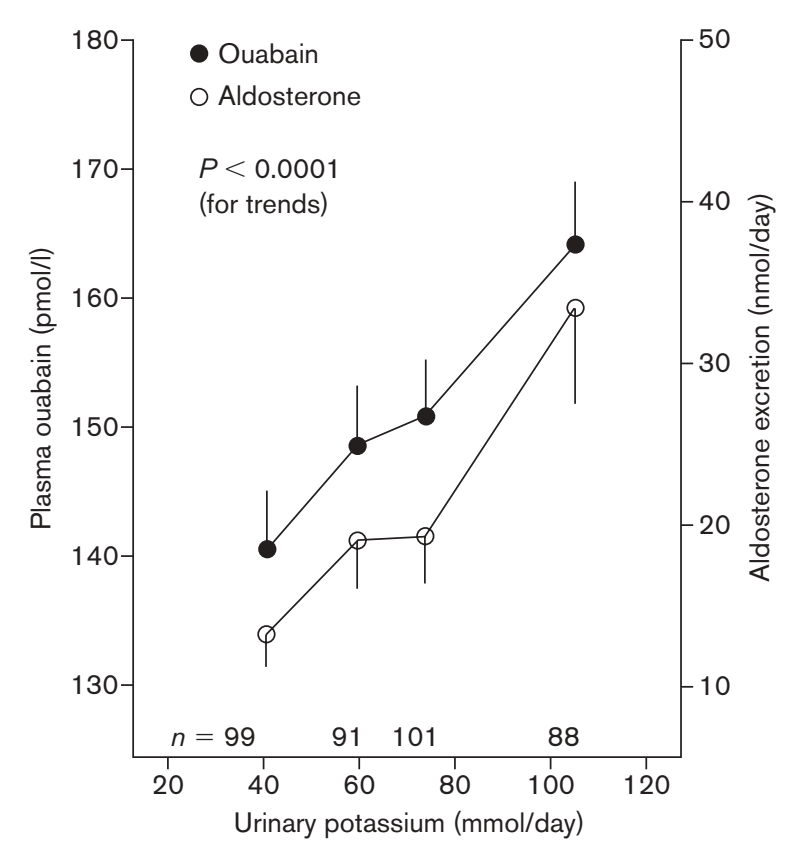

Plasma ouabain concentration and urinary aldosterone excretion in quartiles of urinary potassium excretion. Filled and open symbols represent mean values of plasma ouabain concentration and urinary aldosterone excretion, respectively, with adjustments applied for gender, smoking and the $\alpha$-adducin Gly460Trp polymorphism. Vertical lines denote standard errors. $n$ indicates number of subjects per quartile.

plasma ouabain or urinary sodium excretion $(P>0.23)$ when the latter two measurements were considered in isolation. However, both before and after adjustment, we observed a statistically significant interaction between plasma ouabain and urinary sodium excretion in relation to systolic blood pressure and diastolic blood pressure, irrespective of whether plasma ouabain and urinary sodium excretion were analysed as continuous (Fig. 3) $(P<0.02)$ or categorical variables (Fig. 4$)(P<$ $0.02)$.

We derived quantitative estimates of the blood pressure effects from the categorical analysis (Fig. 4). In 190 subjects whose plasma ouabain was equal to or less than $140 \mathrm{pmol} / \mathrm{l}$ (median), each $50 \mathrm{mmol} /$ day increment in urinary sodium excretion was associated with an increase in blood pressure averaging $2.2 \mathrm{mmHg}(95 \%$ CI, $0.7-3.6 \mathrm{mmHg} ; P=0.004)$ systolic and $1.4 \mathrm{mmHg}$ (95\% CI, $0.3-2.5 \mathrm{mmHg} ; P=0.01$ ) diastolic. In contrast, in subjects whose plasma ouabain was higher than $140 \mathrm{pmol} / \mathrm{l}$, the association between blood pressure and urinary sodium excretion was not statistically significant $(P \geqslant 0.10)$.

\section{Sensitivity analysis}

We repeated our analyses after exclusion of subjects on antihypertensive drugs, oral contraceptives or hormonal
Fig. 3
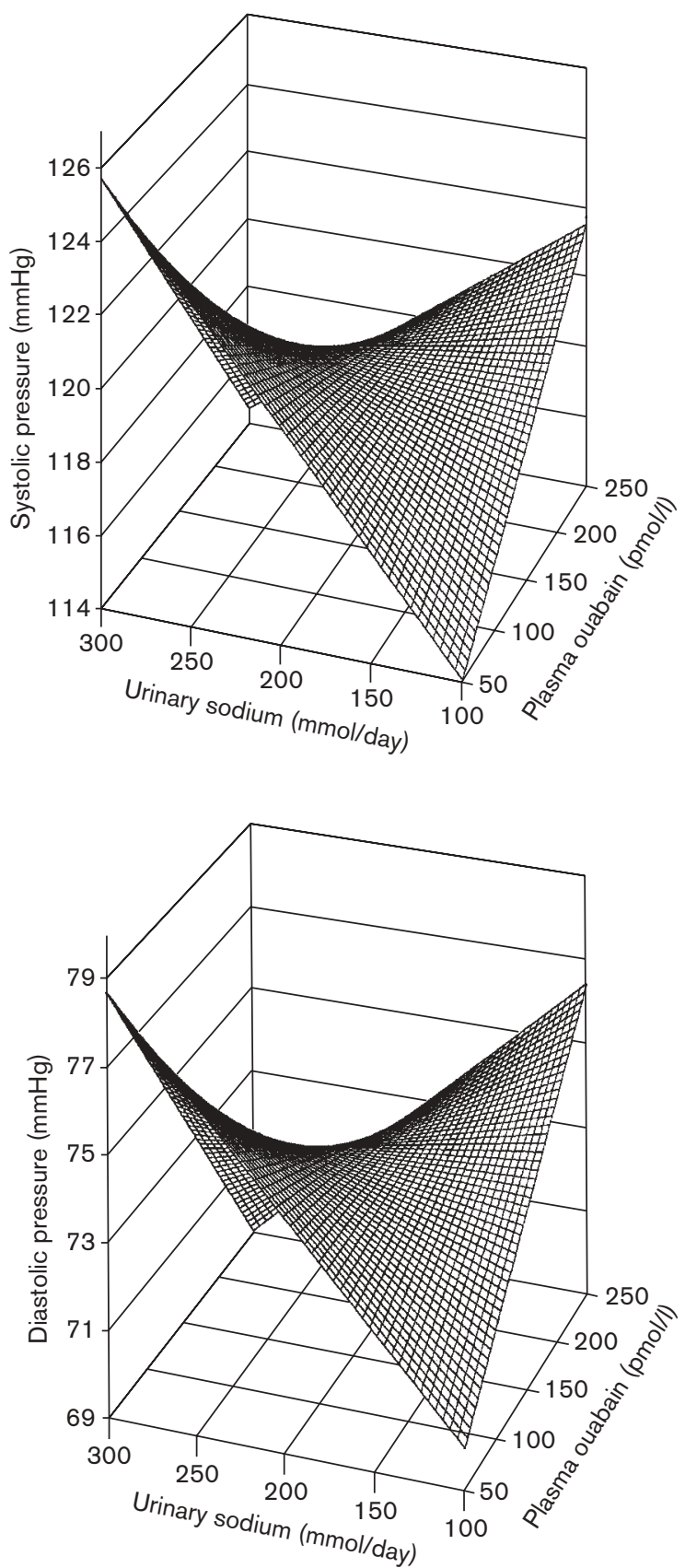

Continuous relationship between blood pressure, plasma ouabain concentration and urinary sodium excretion. Using multiple linear regression, systolic blood pressure (upper) and diastolic blood pressure (bottom) were standardized to female gender, 40.2 years of age (mean), $24.7 \mathrm{~kg} / \mathrm{m}^{2}$ body mass index (mean), non-smoking, no intake of alcohol, and no use of antihypertensive drugs or oral contraceptives. The $P$ values for interaction between urinary sodium excretion and plasma ouabain concentration were 0.02 and 0.01 for systolic blood pressure and diastolic blood pressure, respectively.

replacement therapy. In these 273 untreated subjects, our findings remained unaltered. The plasma ouabain concentration ( \pm standard error) was $146.2 \pm 3.6$, $157.2 \pm 4.5$ and $181.2 \pm 11.5 \mathrm{pmol} / \mathrm{l}$ in GlyGly, GlyTrp 
Fig. 4

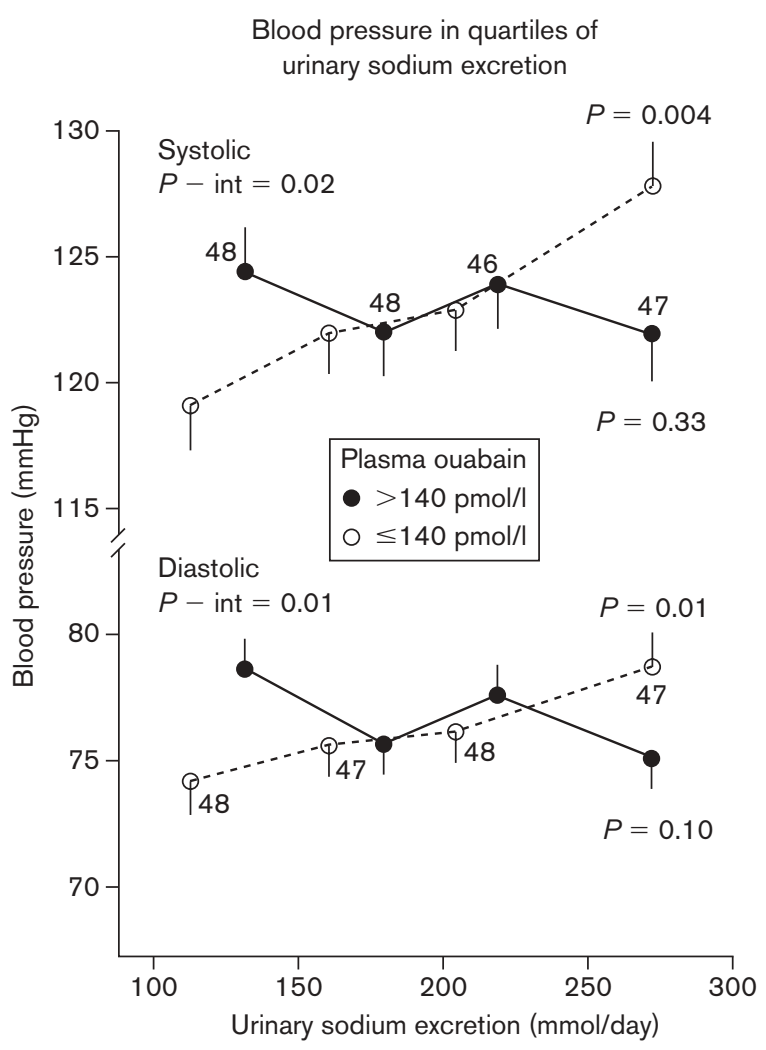

Associations between blood pressure, plasma ouabain concentration and urinary sodium excretion. Filled (plasma ouabain $>140 \mathrm{pmol} / \mathrm{l}$, median) and open symbols ( $\leqslant 140$ pmol/l) represent the mean values of blood pressure in quartiles of urinary sodium excretion. The number of subjects in each quartile of urinary sodium excretion is shown alongside the symbols. Vertical lines denote standard errors. Values were adjusted for gender, age, age ${ }^{2}$, body mass index, smoking, alcohol intake, and use of antihypertensive drugs and/or oral contraceptives. Significance levels for trends $(P)$ and interactions $(P$ int) are given.

and TrpTrp subjects ( $P=0.002$ for trend), respectively, and it was $8.2 \mathrm{pmol} / \mathrm{l}$ higher (95\% CI, $2.9-13.4 \mathrm{pmol} / \mathrm{l}$; $P=0.002)$ for each $25 \mathrm{mmol} /$ day increment in urinary potassium. In 132 untreated subjects whose plasma ouabain was equal to or less than $140 \mathrm{pmol} / \mathrm{l}$, each $50 \mathrm{mmol} /$ day increment in urinary sodium excretion was associated with an increase in blood pressure averaging $1.9 \mathrm{mmHg}$ (95\% CI, $0.2-3.6 \mathrm{mmHg}, \quad P=$ 0.03 ) systolic and $1.6 \mathrm{mmHg}(95 \% \mathrm{CI}, 0.4-2.8 \mathrm{mmHg}$; $P=0.01)$ diastolic.

\section{Discussion}

Our study is the first population-based investigation of endogenous ouabain. We demonstrated that carriers of the mutated $\alpha$-adducin Trp allele had higher plasma ouabain concentration than GlyGly homozygotes. Second, there was a linear and positive association between plasma ouabain and urinary potassium excretion. Third, blood pressure increased with higher urinary sodium excretion in subjects with low plasma ouabain, but not in those with high levels. The observation that smoking is associated with higher plasma ouabain suggests that our measurements of plasma ouabain were accurate. Indeed, decreased oxygen saturation of the blood in experimental animals [19] or in patients with obstructive sleep apnoea [20] has been linked with higher plasma concentration of the endogenous inhibitor of the sodium-potassium pump. The positive relationship between the urinary excretion of aldosterone and potassium also constitutes an internal validation of our study.

One possible interpretation of our findings is that endogenous ouabain might play a central role in the homeostatic regulation of blood pressure in response to changes in sodium intake. Several mechanisms may explain why the relationship between blood pressure and ouabain is positive. First, in sodium-depleted subjects, endogenous ouabain may enhance sodium retention. Several studies [21,22] have shown that low subnanomolar concentrations of ouabain may stimulate, not inhibit, renal $\mathrm{Na}^{+} / \mathrm{K}^{+}$-ATPase. In addition, low concentrations of ouabain may raise the intracellular concentration of free and stored calcium ions, enhance excitation-contraction coupling in vascular smooth muscle cells, and increase peripheral vascular resistance [23]. We also observed a positive association between haematocrit and plasma ouabain. Thus, an increase in blood viscosity may also raise blood pressure [24]. However, whether the relationship between haematocrit and ouabain is causal remains to be elucidated.

During elevated salt intakes, endogenous ouabain may act as a compensatory factor protecting against the development of sodium-sensitive high blood pressure, a proposal consistent with the commonly held view that this substance promotes natriuresis [1]. Carriers of the mutated $\alpha$-adducin Trp allele have a genetically determined higher $\mathrm{Na}^{+} / \mathrm{K}^{+}$-ATPase activity [13], which may induce a volume-dependent hypertension [15] via sodium retention $[15,16]$. This pathogenic mechanism may be counteracted by a feedback increment in circulating ouabain (Fig. 1). In the absence of the compensation by endogenous ouabain, hypertension may develop with increasing body sodium [25,26].

Failure to account for endogenous ouabain as a player in the relationship between blood pressure and salt intake may have confounded the results of earlier studies [15,16,27-33]. The blood pressure-lowering effect of salt restriction differed between trials or subgroups of study subjects [27-33]. For instance, in the Dietary Approaches to Stop Hypertension (DASH) trial, compared with men, women showed a more pronounced blood pressure reduction in response to a low sodium diet [32]. Endogenous ouabain might play 
a part in the determination of this gender difference, because we noticed that women had a lower plasma ouabain concentration than men and that only at low levels of ouabain was blood pressure positively associated with sodium excretion. Furthermore, there is clear experimental evidence that mutation of the $\alpha$ adducin gene enhances proximal renal tubular sodium reabsorption and increases salt sensitivity $[15,16]$. Nevertheless, the results of observational and epidemiological studies were more equivocal [34] with the exception of those in homogeneous groups of low-renin hypertensive patients [35-37]. Our study now supports that endogenous ouabain might act as a hormone compensating for the volume-dependent increase in blood pressure in carriers of the mutated $\alpha$-adducin Trp allele.

The finding that plasma ouabain rises with higher urinary potassium excretion also supports the hypothesis of the participation of the steroid in blood pressure regulation and homeostasis of electrolytes. Blood pressure is inversely correlated with plasma concentration of potassium, exchangeable potassium and total body potassium [26]. Potassium restriction increases blood pressure in normotensive subjects [38] and aggravates hypertension in patients with this disease [39]. A metaanalysis of randomized trials showed that the blood pressure-lowering effect of potassium supplementation occurred when the average urinary sodium excretion was $165 \mathrm{mmol} /$ day or more [40]. Similarly, the DASH trial revealed that a potassium-enriched diet (mean urinary potassium excretion, $80 \mathrm{mmol} / \mathrm{day}$ versus $40 \mathrm{mmol} /$ day) produced a greater blood pressure reduction on high and intermediate salt intake (mean urinary sodium excretion, $144 \mathrm{mmol} /$ day and $107 \mathrm{mmol} /$ day, respectively) than on low salt intake (mean urinary sodium excretion, $67 \mathrm{mmol} / \mathrm{day}$ ) [41]. The difference in blood pressure-lowering effects averaged approximately $3 \mathrm{mmHg}$ systolic and $2 \mathrm{mmHg}$ diastolic.

In conclusion, endogenous ouabain may be a blood pressure modulating factor, possibly released in response to potassium, either inhibiting the pressor effect of an excessive salt intake or counteracting the depressor action of sodium depletion. Our study was observational in nature not designed to reveal causal association, and should therefore be considered as hypothesis generating. Nevertheless, if confirmed by experimental studies and other epidemiological investigations, our findings might have clinical implications for the management of human hypertension and the prevention of cardiovascular disorders.

\section{Acknowledgements}

The FLEMENGHO study would not have been possible without the collaboration of the family physicians of the participants. The municipality Hechtel-
Eksel (Belgium) provided logistic support. The authors acknowledge the expert assistance of Leszek Bieniaszewski MD, Rina Bollen, Lut De Pauw RN, Hilde Celis MD, Elly Den Hond DSG, Primoz Dolenc MD, Paul Drent, Dmitri Emelianov MD, Jerzy Gąsowski MD, Heng Fan, Lieve Gijsbers, Alida Hermans, Tatyana Kuznetsova MD, Muzi Maseko BSC, Agnieszka Olszanecka MD, Katarzyna Stolarz MD, Lutgarde Thijs BSC, Valérie Tikonoff MD, Yvette Toremans, Sylvia Van Hulle RN, and Renilde Wolfs (Study Coordinating Centre, Leuven, Belgium).

\section{References}

1 Schoner W. Endogenous cardiac glycosides, a new class of steroid hormones. Eur J Biochem 2002; 269:2440-2448.

2 Hamlyn JM, Blaustein MP, Bova S, DuCharme DW, Harris DW, Mandel $\mathrm{F}$, et al. Identification and characterization of a ouabain-like compound from human plasma. Proc Natl Acad Sci USA 1991; 88:6259-6263.

3 Ferrandi M, Manunta P, Balzan S, Hamlyn JM, Bianchi G, Ferrari P. Ouabain-like factor quantification in mammalian tissues and plasma. Comparison of two independent assays. Hypertension 1997; 30 886-896.

4 Kawamura A, Guo J, Itagaki Y, Bell C, Wang Y, Haupert GT Jr, et al. On the structure of endogenous ouabain. Proc Natl Acad Sci USA 1999; 96:6654-6659.

5 Schneider R, Wray V, Nimtz M, Lehmann WD, Kirch U, Antolovic R, et al. Bovine adrenals contain, in addition to ouabain, a second inhibitor of the sodium pump. J Biol Chem 1998; 273:784-792.

6 Ferrandi M, Manunta P. Ouabain-like factor: is this the natriuretic hormone? Curr Opin Nephrol Hypertens 2000; 9:165-171.

7 Aperia A. Regulation of sodium/potassium ATPase activity: impact on salt balance and vascular contractility. Curr Hypertens Rep 2001; 3: 165-171.

8 Yuan CM, Manunta P, Hamlyn JM, Chen S, Bohen E, Yeun J, et al. Longterm ouabain administration produces hypertension in rats. Hypertension 1993; 22:178-187.

9 Hamlyn JM, Hamilton BP, Manunta P. Endogenous ouabain, sodium balance and blood pressure: a review and a hypothesis. $J$ Hypertens 1996; 14:151-168.

10 Lopatin DA, Ailamazian EK, Dmitrieva RI, Shpen VM, Fedorova OV, Doris PA, et al. Circulating bufodienolide and cardenolide sodium pump inhibitors in preeclampsia. J Hypertens 1999; 17:1179-1187.

11 Gottlieb SS, Rogowski AC, Weinberg M, Krichten CM, Hamilton BP, Hamlyn JM. Elevated concentrations of endogenous ouabain in patients with congestive heart failure. Circulation 1992; 86:420-425.

12 Tripodi G, Valtorta F, Torielli L, Chieregatti E, Salardi S, Trusolino L, et al. Hypertension-associated point mutations in the adducin alpha and beta subunits affect actin cytoskeleton and ion transport. J Clin Invest 1996; 97:2815-2822.

13 Ferrandi M, Salardi S, Tripodi G, Barassi P, Rivera R, Manunta P, et al. Evidence for an interaction between adducin and $\mathrm{Na}^{+}-\mathrm{K}^{+}$-ATPase: relation to genetic hypertension. Am J Physiol 1999; 277: $\mathrm{H} 1338-\mathrm{H} 1349$.

14 Bundgaard H, Schmidt TA, Larsen JS, Kjeldsen K. $\mathrm{K}^{+}$supplementation increases muscle $\left[\mathrm{Na}^{+}-\mathrm{K}^{+}\right.$-ATPase] and improves extrarenal $\mathrm{K}^{+}$ homeostasis in rats. J Appl Physiol 1997; 82:1136-1144.

15 Cusi D, Barlassina C, Azzani T, Casari G, Citterio L, Devoto M, et al. Polymorphisms of alpha-adducin and salt sensitivity in patients with essential hypertension. Lancet 1997; 349:1353-1357.

16 Manunta P, Burnier M, D'Amico M, Buzzi L, Maillard M, Barlassina C, et al. Adducin polymorphism affects renal proximal tubule reabsorption in hypertension. Hypertension 1999; 33:694-697.

17 Staessen JA, Wang JG, Brand E, Barlassina C, Birkenhäger WH, Herrmann SM, et al. Effects of three candidate genes on prevalence and incidence of hypertension in a Caucasian population. $J$ Hypertens 2001; 19:1349-1358.

18 Staessen JA, Fagard R, Amery A. Life style as a determinant of blood pressure in the general population. Am J Hypertens 1994; 7:685-694.

19 De Angelis C, Haupert GT Jr. Hypoxia triggers release of an endogenous inhibitor of $\mathrm{Na}^{+}-\mathrm{K}^{+}$-ATPase from midbrain and adrenal. Am J Physiol 1998; 274:F182-F188.

20 Paci A, Marrone O, Lenzi S, Prontera C, Nicolini G, Ciabatti G, et al. 
Endogenous digitalislike factors in obstructive sleep apnea. Hypertens Res 2000; 23:S87-S91.

21 Ferrari P, Ferrandi M, Torielli L, Tripodi G, Melloni P, Bianchi G. PST2238: a new antihypertensive compound that modulates $\mathrm{Na}^{+}, \mathrm{K}^{+}$. ATPase and antagonizes the pressor effect of OLF. Cardiovasc Drug Rev $1999 ; 17: 39-57$.

22 Ghysel-Burton J, Godfraind T. Stimulation and inhibition of the sodium pump by cardioactive steroids in relation to their binding sites and their inotropic effect on guinea-pig isolated atria. Br J Pharmacol 1979; 66:175-184.

23 Blaustein MP. Physiological effects of endogenous ouabain: control of intracellular $\mathrm{Ca}^{2+}$ stores and cell responsiveness. Am J Physiol 1993; 264:C1367-C1387.

24 Koenig W, Sund M, Ernst E, Keil U, Rosenthal J, Hombach V. Association between plasma viscosity and blood pressure. Results from the MONICA-Project Augsburg. Am J Hypertens 1991; 4:529-536.

25 Beretta-Piccoli C, Weidmann P, Brown JJ, Davies DL, Lever AF, Robertson JIS. Body sodium and blood volume state in essential hypertension: abnormal relation of exchangeable sodium to age and blood pressure in male patients. J Cardiovasc Pharmacol 1984; 6(suppl 1): S134-S142.

26 Beretta-Piccoli C, Davies DL, Boddy K, Brown JJ, Cumming AM, East BW, et al. Relation of arterial pressure with body sodium, body potassium and plasma potassium in essential hypertension. Clin Sci 1982; 63: 257-270.

27 Midgley JP, Matthew AG, Greenwood CMT, Logan AG. Effect of reduced dietary sodium on blood pressure. A meta-analysis of randomized controlled trials. JAMA 1996; 275:1590-1597.

28 Cutler JA, Follmann D, Allender PS. Randomized trials of sodium reduction: an overview. Am J Clin Nutr 1997; 65(suppl):643S-651S.

29 Graudal N, Galløe AM, Garred P. Effects of sodium restriction on blood pressure, renin, aldosterone, catecholamines, cholesterols, and triglycerides: a meta-analysis. JAMA 1998; 279:1383-1391.

30 Grobbee DE, Hofman A. Does sodium restriction lower blood pressure? BMJ 1986; 293:27-29.

31 Hooper L, Bartlett C, Smith GD, Ebrahim S. Systematic review of long term effects of advice to reduce dietary salt in adults. BMJ 2002; 325:628-636.

32 Vollmer WM, Sacks FM, Ard J, Appel LJ, Bray GA, Simons-Morton DG, et al. Effects of diet and sodium intake on blood pressure: subgroup analysis of the DASH-sodium diet. Ann Intern Med 2001; 135: 1019-1028.

33 Robertson JIS. Dietary salt and hypertension: a scientific issue or a matter of faith ? J Evaluat Clin Pract 2002; 9:1-22.

34 Barlassina C, Lanzani C, Manunta P, Bianchi G. Genetics of essential hypertension: from families to genes. J Am Soc Nephrol 2002; 13(suppl 3):S155-S164.

35 Sugimoto K, Hozawa A, Katsuya T, Matsubara M, Ohkubo T, Tsuji I, et al. Alpha-adducin Gly460Trp polymorphism is associated with low renin hypertension in younger subjects in the Ohasama Study. J Hypertens $2001 ; 20: 1779-1784$.

36 Fisher NDL, Hurwitz S, Jeunemaitre X, Hopkins PN, Hollenberg NK, Williams GH. Familial aggregation of low-renin hypertension. Hypertension 2002; 39:914-918.

37 Mulatero P, Williams TA, Milan A, Fallo F, Rabbia F, Fallo F, et al. Blood pressure in patients with primary aldosteronism is influenced by bradykinin B2 receptor and $\alpha$-adducin genes polymorphisms. J Clin Endocrinol Metab 2002; 87:3337-3343.

38 Krishna GG, Miller E, Kapoor S. Increased blood pressure during potassium depletion in normotensive men. N Engl J Med 1989; 320:1177-1182.

39 Krishna GG, Kapoor S. Potassium depletion exacerbates essential hypertension. Ann Intern Med 1991; 115:77-83.

40 Whelton PK, He J, Cutler JA, Brancati FL, Appel L, Follmann D, et al. Effects of oral potassium on blood pressure. Meta-analysis of randomized controlled clinical trials. JAMA 1997; 277:1624-1632.

41 Sacks FM, Svetkey LP, Vollmer WM, Appel L, Bray GA, Harsha D, et al. Effects on blood pressure of reduced dietary sodium and the dietary approaches to stop hypertension (DASH) diet. N Engl J Med 2001; $344: 3-10$. 